\title{
VISUAL INSPECTION OF CERVIX WITH ACETIC ACID: A GOOD ALTERNATIVE TO PAP SMEAR FOR CERVICAL CANCER SCREENING IN RESOURCE LIMITIED SETING.
}

\author{
Mishal Awan ${ }^{1}$, Iffat Ayoub ${ }^{2}$, Syeda Masooma Bukhari ${ }^{3}$ \\ 1,2,3. House Officer, Nishtar Hospital, Multan. \\ Correspounding Author: masooma.bukh@gmail.com
}

\begin{abstract}
:
Objective: Determine the diagnostic accuracy of visual inspection of cervix (VIA) by using 3\% acetic acid as a screening test for early and timely detection of cervical cancer when histopathology taken as the gold standard of diagnosis. Methodology: This study was conducted at Nishtar Hospital, Multan, and the study design choose for conducting this study was Cross Sectional study method. Study was completed in one year duration from February 2018 to February 2019. All statistical data was entered and analyzed by using SPSS version 23. Frequencies and percentages were calculated and presented for qualitative variables like marital status. Parity, ethnic group and religion. Mean \pm Standard Deviation (SD) was calculated for numerical variables like duration of marriage and age. The diagnostic accuracy, sensitivity specificity and positive predictive value (PPV) and negative predictive value (NPV) was calculated using two into two contingency table and histopathology was taken as the gold standard. Results: Overall, 100\% $(n=320)$ female patients were included, in this study. There were $87.2 \%(n=279)$ patients had poor socio-economic status, while $12.8 \%(n=41)$ had good socio-economic status. The sensitivity, specificity, positive predictive value, negative predictive value and accuracy of VIA and abnormal looking cervix were $81.7 \%, 80.7 \%, 51.5 \%, 48.5 \%$ and $81.3 \%$ respectively. Conclusion: Screening schedules are not planned and followed in Pakistan ever, so VIA is effective and always a useful diagnostic test for cervical cancer, pre-cancerous lesions can be detected at their early stage through VIA and mortality and morbidity can be reduced.
\end{abstract}

Keywords: Cervical Cancer, Visual inspection, Pap smear, Diagnosis.

DOI: $10.7176 / \mathrm{JMPB} / 54-10$

Publication date: April $30^{\text {th }} 2019$

\section{Introduction:}

In developing countries incidence of cervical cancer is more common among women ${ }^{1,2}$. Every year more than 490,000 cases of cervical cancer appear all over the world in developing countries ${ }^{3}$. There are many diagnostic tests to diagnose the disease at early stage to start early treatment to decrease the mortality rate ${ }^{3}$. Disease control rate is increased through screening process; out of many diagnostic tests PAP smear test is one of the effective screening method to diagnose Cervical Cancer ${ }^{4}$.

One of the limitation of this test is, it is not easily available in under developed countries like Pakistan due to lack of Economical Resources 5 . Many other low cost diagnostic techniques are likely been used to investigate such problems in low income countries like Visual Inspection of Cervix after applying Acetic Acid (VIA), Visual inspection after lugol's iodine (VILI) ${ }^{6}$. Visual Inspection of Cervix after applying Acetic Acid is an effective method of differentiating healthy Cervix from non-healthy of diseased Cervix ${ }^{7}$.

According to WHO Visual inspection after applying Acetic Acid Test technique can be used as a substitute of PAP smear cytology for identifying the cervical cancer patients ${ }^{6}$. Visual Inspection of Cervix after applying Acetic Acid (VIA) test is a non-invasive test which gives immediate reporting. Due to this specificity this test can be easily perform to diagnose Cervical Cancer in developing Countries like Pakistan ${ }^{5}$.

Diagnostic Results through PAP smear and VIA has almost same diagnostic results but still it is under process that which screening test should be use as primary screening method to diagnose Cervical Cancer ${ }^{9}$. Other than cervical cancer dysplasia is also an abnormal appearance of cervix but it is not cancer, it can also be diagnosed 
with Pap smear test. Dysplasia may be precancerous presentation of cervix. Another common pre-cancerous presentation is cervical intraepithelial neoplasia and can be diagnosed by biopsy test of cervix. Treatment of these two presentations (SIL and CIN) is usual and can stop the development of cancer. Aim of this study is to find out the cost effective diagnostic test which can be use as primary screening test to diagnose Cervical Cancer.

\section{Methodology:}

This study was conducted at Nishtar Hospital, Multan, and the study design choose for conducting this study was Cross Sectional study method. Study was completed in one year duration from February 2018 to February 2019. After getting Ethical approval study was started in Gynaecology and obstetrical ward of hospital. Females of reproductive age 18-60 years were studied after taking informed consent from study population. Medical history was taken in detailed way and then Physical examination session was also arranged to assess the Cervix by trained staff. Separate room was arranged for maintaining privacy standards of the study personnel's. Procedure was explained to the personnel's to reduce their anxiety level. Sample size was calculated openepi.com by using CI $95 \%$, power of study $80 \%$ and diagnostic accuracy $95.6 \%$.

Patients were positioned in Lithotomy position for Physical Examination of Cervix. Proper light stand was arranged in the examination room to make the inspection area visible. Acetic Acid swab was applied to the Cervix and then cervix area was observed for Acetowhite changes. Changes were noticed in duration of 1 minute. In Diagnostic labeling Acetowhite changes were considered as Positive Test and dull or no changes were considered as negative test for diagnosing Cervical Cancer.

Tissue Biopsy was taken from the positive diagnostic results personnel's and the samples were sent to histopathology lab for further investigation. To analyze the frequencies and percentages all the data was analyzed in SPSS-17. Categorical variables were formed on the basis of Age, Marital Status, religion and ethnic group. Sensitivity and the specificity of the diagnostic test were calculated according to positive predictive value and negative predictive value.

All statistical data was entered and analyzed by using SPSS version 23. Frequencies and percentages were calculated and presented for qualitative variables like marital status. Parity, ethnic group and religion. Mean \pm Standard Deviation (SD) was calculated for numerical variables like duration of marriage and age. The diagnostic accuracy, sensitivity specificity and positive predictive value (PPV) and negative predictive value (NPV) was calculated using two into two contingency table and histopathology was taken as the gold standard.

\section{Results:}

Overall, 100\% $(n=320)$ female patients were included, in this study. There were $87.2 \%(n=279)$ patients had poor socio-economic status, while $12.8 \%(\mathrm{n}=41)$ had good socio-economic status. Nulliparous women were $8.8 \%(n=28), 47.1 \%(n=151)$ were single or multiparous, while $44.1 \%(n=141)$ were grand multipara. The mean age of the patients was $33.14 \pm 7.15$ years. There were $36.9 \%(\mathrm{n}=118)$ patients between $18-30$ years, while majority of the patients i.e. $63.1 \%(n=202)$ between $31-50$ years of age. (Table. 1$)$.

The mean duration of sexual activity, menarche, age at first coitus, age at first pregnancy and parity of the patients was $12.04 \pm 5.81$ years, $11.1 \pm 0.65$ years, $17.16 \pm 2.44$ years, $18.90 \pm 1.66$ years and $5.03 \pm 1.15$ respectively. Vaginal discharge was observed in $54.7 \%(\mathrm{n}=175)$ patients. While lower abdominal pain was noted in $40.6 \%(n=130)$ patients. (Table. 2$)$.

Among VIA positive patients in which cervixes looking abnormal 134 (51.5\%) have positive histopathologic finding and $126(48.5 \%)$ have negative histopathology, similarly among VIA negative and abnormal looking patients $30(50 \%)$ patients have positive and $30(50 \%)$ have negative histopathology (Table- 3 ).

The sensitivity, specificity, positive predictive value, negative predictive value and accuracy of VIA and abnormal looking cervix were $81.7 \%, 80.7 \%, 51.5 \%, 48.5 \%$ and $81.3 \%$ respectively (Table. 4). 
Table-1: Demographic Variables

\begin{tabular}{|c|c|c|}
\hline Characteristics & Frequency & Percentage $(\%)$ \\
\hline \multicolumn{3}{|l|}{ Socio-economic Status } \\
\hline Poor & 279 & 87.2 \\
\hline Good & 41 & 12.8 \\
\hline Total & 320 & 100.0 \\
\hline \multicolumn{3}{|l|}{ Woman type } \\
\hline Nulliparous & 28 & 8.8 \\
\hline Single or multiparous & 151 & 47.1 \\
\hline Grand multipara & 141 & 44.1 \\
\hline Total & 320 & 100.0 \\
\hline \multicolumn{3}{|l|}{ Stratified Age } \\
\hline $18-30$ Years & 118 & 36.9 \\
\hline $31-50$ Years & 202 & 63.1 \\
\hline Total & 320 & 100.0 \\
\hline \multicolumn{3}{|c|}{ Descriptive Statistics (Mean \pm S.D) } \\
\hline Age & \multicolumn{2}{|c|}{$33.14 \pm 7.15$ years } \\
\hline
\end{tabular}

Table-2: Frequencies of Study Variables

\begin{tabular}{|l|c|c|}
\hline \multicolumn{1}{|c|}{ Characteristics } & Frequency & Percentage (\%) \\
\hline Vaginal Discharge & 175 & 54.7 \\
\hline Yes & 145 & 45.3 \\
\hline No & $\mathbf{3 2 0}$ & $\mathbf{1 0 0 . 0}$ \\
\hline \multicolumn{1}{|c|}{ Total } & 130 & 40.6 \\
\hline Lower Abdominal Pain & 190 & 59.4 \\
\hline \multicolumn{1}{|c|}{ No } & $\mathbf{3 2 0}$ & $\mathbf{1 0 0 . 0}$ \\
\hline \multicolumn{2}{|c|}{ Total } & $12.04 \pm 5.81$ years \\
\hline Descriptive Statistics (Mean \pm S.D) & $11.1 \pm 0.65$ years \\
\hline $\begin{array}{l}\text { Duration of Sexual } \\
\text { Activity }\end{array}$ & $17.16 \pm 2.44$ years \\
\hline Menarche & $18.90 \pm 1.66$ years \\
\hline Age at first coitus & \multicolumn{3}{c|}{$5.03 \pm 1.15$} \\
\hline Age at first pregnancy & \multicolumn{2}{c|}{} \\
\hline Parity &
\end{tabular}


Table. 3: Validity of screening test for early diagnosis of cervical cancer

\begin{tabular}{|c|c|c|c|}
\hline \multirow{2}{*}{ VIA $^{*}$} & \multicolumn{3}{|c|}{ Histopathology findings } \\
\cline { 2 - 4 } & Positive & Negative & Total \\
\hline $\begin{array}{c}\text { VIA Positive and } \\
\text { Abnormal looking } \\
\text { cervix }\end{array}$ & $134(51.5 \%)$ & $126(48.5 \%)$ & $\mathbf{2 6 0}$ \\
\hline $\begin{array}{c}\text { VIA Negative but } \\
\text { abnormal looking } \\
\text { cervix }\end{array}$ & $30(50 \%)$ & $30(50 \%)$ & $\mathbf{6 0}$ \\
\hline Total & $\mathbf{1 6 4}$ & $\mathbf{1 5 6}$ & $\mathbf{3 2 0}$ \\
\hline
\end{tabular}

*VIA: Visual inspection of the cervix after acetic acid application

Table-4: Diagnostic Accuracy of VIA

\begin{tabular}{|c|c|}
\hline Diagnostic Measures & Value \\
\hline Sensitivity & $81.7 \%$ \\
\hline Specificity & $80.7 \%$ \\
\hline Positive Predictive Value (PPV) & $51.5 \%$ \\
\hline Negative Predictive Value (PPV) & $48.5 \%$ \\
\hline Accuracy & $81.3 \%$ \\
\hline
\end{tabular}

\section{Discussion:}

Cervical Cancer is considered as one of the emerging health problem among females of reproductive age (10). Every year thousands of cases appear. Its incidence is higher in the developing countries like Pakistan (10). In Pakistan its incidence is about $3.6 \%$ in every year. The most dangerous thing is, people have less awareness about cervical cancer, due to lack of awareness about disease sign and symptoms patients come late to the hospitals specially they approach hospitals at last stages (11).

Different diagnostic tests are performed to diagnose Cervical Cancers. The Diagnostic Test PAP Smear is the most common test in developed countries and can be use as primary diagnostic test for Cervical Cancer Screening in developed Countries, but in under developed countries due to lack of resources this test cannot be use commonly, so this test is not approachable in rural areas and under developed places (12). While Visual Inspection of Cervix after applying Acetic Acid (VIA) Test is use as a substitute of PAP smear in developing countries $(13,14)$.

In our study VIA was positive in $81.2 \%$ patients and among VIA positive patients in which cervixes looking abnormal 134 (51.5\%) have positive histopathologic finding and 126 (48.5\%) have negative histopathology, similarly among VIA negative and abnormal looking patients $30(50 \%)$ patients have positive and $30(50 \%)$ have negative histopathology. In some previous studies VIA positive was reported in 1.7 to $29 \%$ patients $(15,16,17)$.

VIA is a non-invasive test which provide quick results or it is less costly test. So it is a very useful test in developing countries to diagnose Cervical Cancer. This test can easily be performed in rural areas where hospitals do not have so many diagnostic resources. Due to its non-invasive approach this test can be perform easily without creating anxiety to patient. Reporting of this test is quick and based on visual assessment; this property encourages quick diagnosis of Cervical Cancer. 
According to one study $3.1 \%$ females were diagnosed positive for Cervical Cancer through VIA testing on Acetowhite appearance of Cervix (18). Another study was conducted, which showed that $28 \%$ females diagnosed as positive for Cervical Cancer over Acetowhite grading through VIA (19).

In our study sensitivity, specificity, positive predictive value, negative predictive value and accuracy of VIA and abnormal looking cervix were $81.7 \%, 80.7 \%, 51.5 \%, 48.5 \%$ and $81.3 \%$ respectively. In some previous studies sensitivity of VIA noted from $60 \%$ to $100 \%$ and specificity ranged from $36.4 \%$ to $99.1 \%(20,21)$.

Conclusion: Screening schedules are not planned and followed in Pakistan ever, so VIA is effective and always a useful diagnostic test for cervical cancer, pre-cancerous lesions can be detected at their early stage through VIA and mortality and morbidity can be reduced.

\section{References}

1. Blumenthal PD, Gaffikin L, Deganus S, Lewis R, Emerson M, Adadevoh S. Cervical cancer prevention: safety, acceptability, and feasibility of a single-visit approach in Accra, Ghana. Am J Obstet Gynecol 2007;196:407.e1-e9.

2. Jeronimo J, Morales O, Horna J, Pariona J, Manrique J, RubiñosJ, et al. Visual inspection with acetic acid for cervical cancer screening outside of low-resource settings. Revista panamericana de salud pública 2005;17:1-5.

3. Basil JB, Horowitz IR. Cervical carcinoma: contemporare management. Obstet Gynecol Clin North Am 2001;28:727-42.

4. De Vuyst H, Claeys P, Njiru S, Muchiri L, Steyaert S, De Sutter P, et al. Comparison of pap smear, visual inspection with acetic acid, human papillomavirus DNA-PCR testing and cervicography. Int J Gynecol Obstet 2005;89:120-6.

5. Tayyeb R, Khawaja N, Malik N. Comparison of visual inspection of cervix and Pap smear for cervical cancer screening. J Coll Physicians Surg Pak. 2003;13:201-3.

6. Bhatla N, Mukhopadhyay A, Joshi S, Kumar A, Kriplani A, Pandey R et al. Visual inspection for cervical cancer screening; evaluation by doctor versus paramedical worker. Indian J Cancer 2004;41:32-6.

7. Soutter W, Dina R. Premalignant disease of the genital tract. Gynaecology London: Churchill Livingstone, 2003;569-71.

8. Doh A, Nkele N, Achu P, Essimbi F, Essame O, Nkegoum B. Visual inspection with acetic acid and cytology as screening methods for cervical lesionsin Cameroon. Int J Gynecol Obstet. 2005;89:167-73.

9. Goel A, Gandhi G, Batra S, Bhambhani S, Zutshi V, Sachdeva P. Visual inspection of the cervix with acetic acid for cervical intraepithelial lesions. Int J Gynecol Obstet 2005;88:25-30.

10. Munoz N, Bosch FX, de Sanjose S, Herrero R, Castellsagué X, Shah KV, et al. Epidemiologic classification of human papillomavirus types associated with cervical cancer. $\mathrm{N}$ Engl $\mathrm{J}$ Med. 2003;348:518-27.

11. Abbasi AN, Zahid S, Bhurgri Y, Ali N, Karsan F. Nasopharyngeal Carcinoma-An Update of Treatment and Acute Radiation Induced Reactions from a Tertiary-Care Hospital in Pakistan. Asian Pac J Cancer Prev 2011;12:735-8.

12. Bhatla N, Mukhopadhyay A, Kriplani A, Pandey R, Gravitt PE, Shah K, et al. Evaluation of adjunctive testsfor cervical cancerscreening in low resource settings. Indian J Cancer 2007;44:51.

13. Cronje H. Screening for cervical cancer in the developing world. Best Pract Res Clin Obstet Gynaecol 2005;19:517-29.

14. Szarewski A. Cervical screening by visual inspection with acetic acid. Lancet 2007;370:365-6. 
15. Albert S, Oguntayo O, Samaila M. Comparative study of visual inspection of the cervix using acetic acid (VIA) and Papanicolaou (Pap) smearsfor cervical cancerscreening. Ecancer medical science. $2012 ; 6: 262$.

16. Bomfim S, Santana-Franco E, Bahamondes L. Visual inspection with acetic acid for cervical cancer detection. Int J Gynecol Obstet 2005;88:65-6.

17. Sankaranarayanan R, Wesley R, Somanathan T, Dhakad N, Shyamalakumary B, Amma NS, et al. Visual inspection of theuterine cervix after the application of acetic acid in the detection of cervical carcinoma and its precursors. Cancer 1998;83:2150-6.

18. Megevand E, Denny L, Dehaeck K, Soeters R, Bloch B. Acetic acid visualization of the cervix: an alternative to cytologic screening. Obstet Gynecol 1996;88:383-6.

19. Belinson J, Pretorius R, Zhang W, Wu L, Qiao Y, Elson P. Cervical cancer screening by simple visual inspection after acetic acid. Obstet Gynecol 2001;98:441-4.

20. Rana T, Zia A, Sher S, Tariq S, Asghar F. Comparative Evaluation of PAP Smear and Visual Inspection of Acetic Acid (VIA) in CervicalCancer Screening Program in Lady Willingdon Hospital, Lahore.Ann King Edward Med Univ. 2010;16:S104-7.

21. Mahmud G, Tasnim N, Iqbal S. Comparison of Visual Inspection with acetic acid and Pap smear in cervical cancer screening at a tertiary care hospital. J Pak Med Assoc 2013;63: 1013-6. 